UDK 528.422 .1

\title{
ACCURACY, TIME COST AND TERRAIN INDEPENDENCE COMPARISONS OF LEVELLING TECHNIQUES
}

\author{
Khalid L. A. EL-ASHMAWY \\ Department of Civil Engineering, Al-Matria Faculty of Engineering, \\ Helwan University Matria, 11718 Cairo, Egypt. \\ Department of Civil Engineering, College of Engineering and Islamic Architecture, \\ Umm Al-Qura University, Makkah, Saudi Arabia \\ E-mail:khalid85_2002@yahoo.com
}

Received 18 June 2014; accepted 9 September 2014

\begin{abstract}
Levelling techniques is classified as geometric levelling, trigonometric levelling and GPS/Levelling depending on used instruments or the methods applied. Accuracies of geometric levelling with using three equipments (Leica NA-720 optical level, Topcon RL-VH4G2 laser level and Leica NA-3003 digital level), the trigonometric levelling with using two equipments (Topcon GTS710 total station and Topcon Imaging Station) and GPS/levelling with using Sokkia GSR2600 receiver were investigated to determine their performances against precise levelling that yields the most precise results. For this purpose, measurements were taken at hundred points on the ground of a well-protected site. The comparison of the results was performed based on accuracy, time cost and terrain independence. The comparison shows that levelling using digital level produces the closets results to precise levelling results, the time cost of GPS/levelling was $74 \%$ and $41 \%$ less than geometric and trigonometric levelling respectively, and trigonometric and GPS/levelling are independent of the terrain surveyed.
\end{abstract}

Keywords: levelling, digital level, laser level, GPS, accuracy.

\section{Introduction}

Levelling is an operation that is used for determining the elevations of points or the differences in height between points on the earth's surface. This operation is extremely vital for deriving necessary data required for various engineering designs, mapping, and construction. Data from a finished level survey are used to (1) design roads, highways, and airfields; (2) develop topographic maps, showing the general relief of the ground; (3) calculate volume of earthwork for various engineering projects that involve earth cut and fill operations; (4) lay out construction projects; and (5) monitor already constructed structures such as buildings, dams, bridges and airfields.

In levelling, a level reference surface, or datum, is established, and an elevation is assigned to it. This datum may be assigned an assumed elevation, but true elevation is required for the establishment of a bench mark (BM). A series of properly established BMs is therefore the framework of any vertical control (Ghilani, Wolf 2012).
There are a lot of surveying techniques for determining elevations or height differences. These techniques are classified as geometric levelling, trigonometric levelling, and GPS/Levelling according to used surveying instruments and applied measurement method (Ceylan et al. 2005).

Geometric levelling is the determination of the height differences by using level and hold vertical rods. It may firstly appear a method as a very simple and yielding the best result method. However, the practical applications have shown that carrying out of this method is very difficult on the rough ground and sensitive to regular or irregular model errors. The preventative measures must be taken to eliminate or reduce model errors stemmed from instrumental and outer surroundings. If it is not, these situations decrease the survey velocity, thus the cost of surveying rises (Ceylan et al. 2005).

Broadly speaking, there are four classes of level (Ghilani, Wolf 2012):

- Optical level: this is used by builders and engineers. It uses graduated staffs in which the 
smallest graduation is $1 \mathrm{~cm}$. Millimetres must be estimated, and the accuracy of a single reading will be about $2-3 \mathrm{~mm}$.

- Precise level: this is a modification of the optical level in which a parallel plate micrometer is placed in front of the objective lens. This allows the image of the staff graduation to be moved up or down by very small measurable amounts. For sight lengths of fewer than $50 \mathrm{~m}$, single reading accuracies of $0.02 \mathrm{~mm}$ to $0.03 \mathrm{~mm}$ may be achieved.

- Laser level: it works by generating a laser beam inside a protective housing, up to a spinning floating mirror which sends out the laser light over a reasonable distance (100-300 $\mathrm{m}$ or so) as a truly horizontal beam. The laser level uses a special detector which is attached to a standard graduated staff. The detector is moved up and down the staff until the audible signal indicates it is at the precise height of the laser beam. Most detectors emit a series of beeps that get faster and faster as the detector is approaches the height of the laser beam. The sound changes to a continuous beep when at the exact level to detect the laser.

- Digital level: it is similar in appearance to automatic levels, a compensator establishes a horizontal line and this is done by centralising a circular bubble with the foot screws. The main difference between digital level and other levels is that the staff readings are taken and recorded automatically. This type of level uses a special bar-coded staff. The image of the staff passes through the objective lens and then via a beam splitter to a photo-detector array, where it is digitised. The microprocessor compares this image to a copy of the bar code and calculates the staff reading, which is displayed and/or stored. It can also display the horizontal distance to the staff. The sensitivity of the device is such that single reading accuracies of $0.2 \mathrm{~mm}$ to $0.3 \mathrm{~mm}$ can be achieved, and sight lengths can be extended up to $100 \mathrm{~m}$. The advantages of digital levels are that observations are taken without the need to read a staff or record anything by hand. Introducing this automation removes two of the most common errors when levelling, reading the staff incorrectly and writing down the wrong value in the field book. The on-board computer also calculates the heights required so that the possibility of making a mistake is removed. This makes the digital level much faster to use.
Trigonometric levelling often is necessary where accurate elevations are not available or when the elevations of inaccessible points must be determined. In trigonometric levelling, height differences are computed by using vertical angle and distance. With development of the electronic total stations that are able to observe vertical angle and distance by high accuracy the trigonometric levelling has just updated again together.

There are two types of total station (Topcon 2013):

- Single point total station: the total stations take single-point measurements without targets (without reflector or reflectorless) or with targets (mirror, prism or adhesive labels). The points can be surveyed point by point and the positions are automatically saved for later downloading and processing.

- Laser scanner: the Laser scanner belongs to the new devices on the market of surveying instruments. However, a laser scanning machine can be considered as a high automation reflectorless total station; by means of a laser based measurement of distance and accurate angular movement, a target object is sampled in a regular mesh of 3D points. The time-saving benefit of this technique is considerable. Points can be measured at a rate of 20 points per second or more, and there is no waiting for a rod person to arrive at the point.

GPS/Levelling is the most recent and advanced method which is used in the determination of elevations and height differences (Marin et al. 2008). In GPS, positions can be determined in the sense of point positioning and relative positioning. With point positioning the coordinates of points are determined with respect to a well defined coordinate system usually by three coordinate values. On the other hand, with relative positioning the coordinates of points are determined with respect to another point, taking one point as the origin of a local coordinate system. As such, relative positioning is the most precise GPS positioning because this method removes most of the errors by utilizing the differences in either the code or carrier phase ranges. Relative positioning techniques currently being used in surveying include static, rapid static, pseudo-kinematic, kinematic, and real-time kinematic methods. However, for more detailed information see (Berber et al. 2012).

Having outlined the main surveying techniques for levelling, a keen surveyor or civil engineer will want to know the suitable technique and its instruments when the accuracy of derived elevations is concerned. Also the surveyor wants to know the relative merits and demerits of each technique and its range of 
possible applications. For these reasons, levelling techniques have been studied extensively over the years and examples are outlined below.

Ceylan et al. (2005) analysed the geometric levelling with using different three equipments (Wild N3 precise level, invar rods, Sokkia B2 automatic level and wooden rods, Sokkia SDL 30M digital level and bar coded aluminium rods), trigonometric levelling with using different two equipments (Wild T2 theodolite for vertical angle measurements and Topcon GTS 701 electronic total station for distance measurements, only Topcon GTS 701 electronic total station for vertical angle and distance measurements) and GPS/levelling with using Leica 9500 receiver.

Investigation of the height accuracy of using different levels was carried out by Fahd et al. (2007) and El Hassan (2011). Fahd et al. (2007) used three levelling instruments of different designs, an NA2 optical level from Leica, an LP3A laser level from Sokkia and an SDL30 digital level from Sokkia, while El Hassan (2011) used three different levels: NA730-Leica optical automatic level, SDL30-Sokkia digital level and DNA03-Leica digital level.

A comparison between a survey carried out using a Differential Global Positioning System (DGPS) and a total station for elevation heights determination was conducted by Marin et al. (2008). Furthermore, Ke-liang et al. (2010) considered the trigonometric levelling using Leica TCA2003 high-precision total station for getting the heights of necessary points and the trigonometric levelling accuracy.

Form above, it is clear that there is not a single publication comparing the accuracies of the above mentioned levelling techniques especially with using modern instruments. Hence, this study utilizes the geometric levelling with using different three equipments (Leica NA 720 automatic level, Topcon RL-VH4G2 automatic laser and Leica NA 3003 digital level), the trigonometric levelling with using different two equipments (Topcon GTS710 total station and Topcon Imaging Station IS201) and GPS/levelling with using Sokkia GSR2600 receiver. The results of each method are compared with the results of precise levelling using Leica NA2 automatic level with a Leica $(10 \mathrm{~mm})$ GPM3 parallel plate micrometer attachment and a GPLE3 geodetic invar staff with $10 \mathrm{~mm}$ graduations. In addition, comparison of the time cost and terrain independence between the levelling methods is included in the current study.

\section{Case study}

The case study for the present work was chosen in the campus area of Umm Al-Qura University, Makkah, Saudi Arabia. The area is approximately $900 \mathrm{~m}$ by $800 \mathrm{~m}$. The longer dimension runs roughly in the east direction. The height differences in the area is about $14.00 \mathrm{~m}$ and mean terrain altitude is $285.00 \mathrm{~m}$ above the mean sea level.

The area contains two control points. The control point numbers, ground coordinates and standard errors are available.

\section{Instruments used in the study}

Four different types of level were used in geometric levelling. Table 1 shows some of the characteristics of the used levels. First equipment has Leica NA2 automatic level with a Leica $(10 \mathrm{~mm})$ GPM3 parallel plate

Table 1. Some characteristics of the used levels

\begin{tabular}{|c|c|c|c|c|}
\hline Level & $\begin{array}{c}\text { Leica NA2 } \\
\text { (optical - precise) }\end{array}$ & $\begin{array}{l}\text { Leica NA } 720 \\
\text { (optical) }\end{array}$ & $\begin{array}{l}\text { Topcon RL-VH4G2 } \\
\text { (laser) }\end{array}$ & $\begin{array}{l}\text { Leica NA } 3003 \\
\text { (digital) }\end{array}$ \\
\hline Measuring range & up to $150 \mathrm{~m}$ & up to $150 \mathrm{~m}$ & up to $300 \mathrm{~m}$ & $1.3-100 \mathrm{~m}$ \\
\hline Telescope magnification & $32 x$ & $20 x$ & & $24 \mathrm{x}$ \\
\hline Display & optical & optical & $\mathrm{LCD}$ & LCD \\
\hline Micrometer attachment & $\begin{array}{c}10 \mathrm{~mm} \text { GPM3 parallel } \\
\text { plate }\end{array}$ & & & \\
\hline Staff & $\begin{array}{l}\text { GPLE3 geodetic invar } \\
\text { staff with } 10 \mathrm{~mm} \\
\text { graduations }\end{array}$ & $\begin{array}{c}\text { Telescopic aluminium } \\
\text { level staff } 5 \text { meter in } \\
\text { length }\end{array}$ & $\begin{array}{c}\text { Telescopic aluminium } \\
\text { level staff } 5 \text { meter in } \\
\text { length }\end{array}$ & $\begin{array}{l}\text { Leica bar coded staff } \\
4 \text { meter in length }\end{array}$ \\
\hline Means of levelling & $\begin{array}{l}\text { Automatic } \\
\text { compensator }\end{array}$ & $\begin{array}{l}\text { Automatic } \\
\text { compensator }\end{array}$ & $\begin{array}{l}\text { Automatic } \\
\text { compensator }\end{array}$ & $\begin{array}{l}\text { Automatic } \\
\text { compensator }\end{array}$ \\
\hline $\begin{array}{l}\text { Accuracy (standard } \\
\text { deviation) }\end{array}$ & $\pm 0.3 \mathrm{~mm} / \mathrm{km}$ & $\pm 2.5 \mathrm{~mm} / \mathrm{km}$ & $\pm 2.0 \mathrm{~mm} / 20 \mathrm{~m}$ & $\pm 0.4 \mathrm{~mm} / \mathrm{km}$ \\
\hline
\end{tabular}


micrometer attachment and a GPLE3 geodetic invar staff with $10 \mathrm{~mm}$ graduations (Leica 2013). Second equipment has Topcon RL-VH4G2 automatic laser level used with a laser detector unit (LS-80G) and aluminium staff (Topcon 2013). Third equipment has one Leica NA 3003 digital level and two bar coded aluminium rod that is four meter in length. Fourth equipment has one Leica NA 720 automatic level with five meter in length aluminium staff. All rules that must be taken into consideration were carried out carefully in the geometric levelling surveys (Moffitt, Bouchard 1992).

Two different equipments were used in the trigonometric levelling. The first equipment is single point total station and has one Topcon GTS710 total station, five prisms, and target table. Table 2 shows the specifications of the used total station in this research.

Table 2. Topcon GTS710 total station specifications

\begin{tabular}{|c|c|c|c|}
\hline \multicolumn{2}{|c|}{ Angular measurements } & \multicolumn{2}{c|}{$\begin{array}{c}\text { Infrared distance } \\
\text { measurement (IR) }\end{array}$} \\
\hline $\begin{array}{c}\text { Minimum } \\
\text { reading }\end{array}$ & $\begin{array}{c}\text { Standard } \\
\text { deviation }\end{array}$ & $\begin{array}{c}\text { Measuring } \\
\text { range with } \\
\text { circular prism }\end{array}$ & $\begin{array}{c}\text { Standard } \\
\text { deviation }\end{array}$ \\
\hline $1^{\prime \prime}$ & $1^{\prime \prime}$ & $2400 \mathrm{~m}$ & $\begin{array}{c} \pm(2 \mathrm{~mm}+ \\
2 \mathrm{ppm})\end{array}$ \\
\hline
\end{tabular}

The second equipment is laser scanner total station and consists of Imaging Station (IS-201) by Topcon Inc (Hamzah, Said 2011; Topcon 2013). Some specifications of Imaging Station used in this research are shown in Table 3.

Table 3. Specifications of the Topcon image station IS-201

\begin{tabular}{|l|c|l|c|}
\hline $\begin{array}{c}\text { Minimum } \\
\text { angle } \\
\text { reading }\end{array}$ & $1^{\prime \prime} / 0.5^{\prime \prime}$ & $\begin{array}{c}\text { Standard } \\
\text { deviation } \\
\text { of angle } \\
\text { measurement }\end{array}$ & $\pm 1^{\prime \prime}$ \\
\hline $\begin{array}{l}\text { Maximum } \\
\text { automatic } \\
\text { tracking } \\
\text { speed }\end{array}$ & $15^{\circ} / \mathrm{sec}$ & $\begin{array}{l}\text { Automatic } \\
\text { collimating } \\
\text { area }\end{array}$ & $\pm 5^{\circ}$ \\
\hline $\begin{array}{l}\text { Measuring } \\
\text { principle }\end{array}$ & $\begin{array}{l}\text { Time of } \\
\text { flight }\end{array}$ & $\begin{array}{l}\text { Scanner field } \\
\text { of view }\end{array}$ & $33^{\circ} \times 33^{\circ}$ \\
\hline $\begin{array}{l}\text { Scanning } \\
\text { range }\end{array}$ & $150 \mathrm{~m}$ & $\begin{array}{l}\text { Scanning } \\
\text { speed }\end{array}$ & $\begin{array}{r}\text { Tyax } 20 \mathrm{points} / \mathrm{sec} \\
\text { Typical }\end{array}$ \\
\hline $\begin{array}{l}\text { Scanning } \\
\text { standard } \\
\text { deviation }\end{array}$ & $\pm 5 \mathrm{~mm}$ & $\begin{array}{l}\text { Scanning } \\
3 \mathrm{D} \text { point } \\
\text { accuracy }\end{array}$ \\
\hline
\end{tabular}

Five Sokkia GPS receiver and set were used in GPS/levelling surveys. Table 4 summarizes some specifications for the used GPS unit (Sokkia 2013).
Table 4. Specifications for Sokkia GSR2600 GPS receiver

\begin{tabular}{|c|c|c|c|}
\hline Dimension & $\begin{array}{c}\mathrm{D} 153 \times \mathrm{W} 160 \times \\
\mathrm{H} 70 \mathrm{~mm}\end{array}$ & TYPE & GPS RTK \\
\hline Weight & $1.3 \mathrm{~kg}$ & Model & GSR2600 \\
\hline Accuracy & $\begin{array}{c}1.0 \mathrm{~cm}+1 \mathrm{ppm} \\
(\text { horizontal })(1 \sigma) \\
2.0 \mathrm{~cm}+1 \mathrm{ppm} \\
(\text { vertical })(1 \sigma)\end{array}$ & $\begin{array}{l}\text { Antenna } \\
\text { type }\end{array}$ & $\begin{array}{l}\text { Radial IS } \\
\text { (Base) } \\
\text { SK-600 } \\
\text { (Rover) }\end{array}$ \\
\hline $\begin{array}{l}\text { Initia- } \\
\text { lization }\end{array}$ & $\begin{array}{c}<1 \text { minute } \\
\text { (confidence } \\
99.99 \%)\end{array}$ & $\begin{array}{c}\text { Antenna } \\
\text { measurement } \\
\text { method }\end{array}$ & $\begin{array}{c}\text { Slant (Base) } \\
\text { Vertical } \\
\text { (Rover) }\end{array}$ \\
\hline
\end{tabular}

\section{Area surveys}

A series of one hundred independent points were selected at random positions over the area of the case study. The maximum and minimum distances between points were $48.43 \mathrm{~m}$ and $17.36 \mathrm{~m}$ respectively. The elevations of these points were measured using the different levelling methods as outlined briefly below.

\subsection{Levelling using precise level}

The elevations of the points were measured applying precise levelling technique using a recently-adjusted Leica NA2 level in conjunction with a $10 \mathrm{~mm}$ Leica GPM3 parallel plate and GPLE3 invar levelling rod. In establishing the elevations of the points, some precaution measures were taken during observations (Fahd et al. 2007). For example, the observer placed the level midway (to within $\pm 0.1 \mathrm{~m}$ ) between backsights and foresights in an attempt to reduce the effects of residual collimation errors and the small errors contributed by curvature and refraction. The line of sight was always kept at least 1 $\mathrm{m}$ from the ground in order to avoid grazing rays. Also from experience of the author, all observations were conducted in early mornings or late afternoons in order to make use of the less turbulent atmosphere at these times.

The process of precise levelling began at the control point of known elevation. The level was set up midway between the control point and a point whose elevation was to be measured. The level rod was set vertically on the control point, parallel plate of the micrometer attachment was adjusted and the staff reading was read and recorded as backsight. The rod was then moved to the second point, set vertically, adjust the parallel plate and the staff reading was read and recorded as foresight.

The level was then moved ahead, and the process was repeated, using the last point as a turning point so it can be used as new benchmark. This process was repeated, in leapfrogging fashion, until the staff readings on all elevation points were read and recorded. 
The rise-and-fall method of reduction was used and the usual arithmetic checks were made (Ghilani, Wolf 2012). The computed misclosure of this part of the test satisfied the requirements of first order class I levelling standards published by the Federal Geodetic Control Committee (FGCC) of the U.S.A. i.e. better than $\pm 4 \sqrt{\mathrm{K}} \mathrm{mm}$ where $\mathrm{K}$ is level circuit length in $\mathrm{km}$ (Moffitt, Bouchard 1992). The misclosure was then distributed by a straight-line interpolation process (Caltrans 2006) to give the "true" or "most probable" elevations of the points. The elevations of precise levelling were assumed as true values in computation of the accuracies of measurements that were made by each tested method of levelling.

\subsection{Levelling using optical level}

For determining the elevations of the points using optical level, the location to set up the tripod was chosen where the ground is solid and many planned survey points can be observed. The tripod was set up and the automatic level was attached on the tripod and levelled. Once the level was set up, the staff was set up on the control point, the staff reading was read and recorded as backsight. Because the used graduated staffs in which the smallest graduation is $1 \mathrm{~cm}$ the millimetres must be estimated to increase the accuracy of observations.

The staff readings on other elevations points were made by putting the rod on each point, reading the staff and estimating the millimetres, and recording it as intermediate sight.

In case of moving the level, the set up was repeated relative to a new benchmark. Before moving the level, a foresight to a stable turning point should be done so it can be used as new benchmark.

The rise-and-fall method of reduction was used to calculate the elevation of each point and the usual arithmetic checks were made.

\subsection{Levelling using laser level}

For determining the elevations of the points using laser level, the location to set up the tripod was chosen where the laser will reach as many planned survey points as possible. The tripod was set up and the laser level was attached on the tripod, turned on, self-levelled and started spinning. The laser sensor was attached to the rail bracket and slided it down the rail on the stadia rod. The sensor lock was secured at one position on the rail.

Once the level was set up, the staff was set up on the control point, the sensor lock was loosened, and the laser sensor was moved vertically along the staff until it emitted a constant tone, the sensor was locked in place and the staff reading was read and recorded as backsight.

The staff readings on other elevations points were made by putting the rod on each point, loosening the sensor and moving it up or down until it had a continuous tone, reading the staff and recording it as intermediate sight.

In case of moving the level, the set up was repeated relative to a new benchmark. Before moving the level, a foresight to a stable turning point should be done so it can be used as new benchmark.

The rise-and-fall method of reduction was used to calculate the elevation of each point and the usual arithmetic checks were made.

\subsection{Levelling using digital level}

Using the digital level for the determination of the elevations of points was started by selecting a suitable place for setting up the tripod. The tripod was set up with the top close to horizontal, and the digital level was mounted with the tripod screw.

The unit was powered on, self levelled, Menu button was pressed and Line Levelling- BIF method (Backsight, Intermediate, Foresight) was selected. This option is used when there are lot of points to be observed from the same level set up. Another method is the BF, apparently for simple line levelling where the instrument is moved between each staff location.

Once the level was set up and the observing method was selected, the first staff reading was the backsight to a control point. When completing the reading, the Menu button was pressed to accept the reading.

The staff was set up on other elevations points and a sequence of intermediate points was collected. After finishing with intermediate sightings and surveying a foresight to a turning point (to later backsight to) was required, the menu was used to turn Intermediate Sight Off and then shoot the foresight. The elevation of the turning point was kept on the instrument memory to be used as a control point for the next setting up of the level.

After finishing the field work, levelling software LEICA LevelPak was used for managing and downloading the level data and points numbers and elevations.

\subsection{Levelling using total station}

The collection of information on case study area was performed in two steps. The first step was started by 
accurate positioning of the instrument on the ground control points, accurate levelling the instrument using electronic level and measurement of the instrument height to relate the location of the instrument to the known ground coordinates. The backsight (BS) target was positioned over the second ground control point and its height was measured to relate the target location to the ground coordinates. The backsight target was observed by the total station to orientate the survey.

The second step consisted of observing the desired points, called sideshots, by moving the prism with its pole on the elevation points. From these sideshots, three-dimensional coordinates can be computed. The two steps were repeated until surveying and recording all elevation points for later processing.

All data obtained from the field was downloaded into computer using the capabilities of the available software with the total station. The coordinates of the elevation points were exported to an ASCII file to be processed and analysed.

\subsection{Levelling using image station (IS)}

Before the data acquisition using scanning total station took place, site-visit was made to prepare the required information for observation and to test the suitability of the location of the control points. The procedure for scanning the ground surface must be done on suitable control points to ensure an accurate scan of the study area will be picked up.

The IS was positioned over the control point and levelled. The second control point was the backsight to be used to orientate the survey. This step is necessary to be sure that the collected data is in the same coordinate system of the control points.

Once the position of the IS has been satisfied, the first step was to take a digital image of the viewed area. The next step was to adjust the exposure of the digital photo so that the viewed elevation points can be easily identified.

Once the exposure was adjusted accordingly the IS became ready to perform a laser scan. This step involved the selection of the required grid size with interval of $5 \times 5 \mathrm{~m}$ to generate spatial data coverage.

Six separate scans from different locations were required to ensure full coverage of the case study. Each scan took approximately 5 minutes and after the scan was taken a check shot was taken to the back sight to make sure the IS has not moved or been dislodged while scanning. Finally, since IS scanner enables the user to collect from the scanner wide angle camera images within the user-defined scan area, the images were stitched together and the scanned data was shown over the images on the IS touch screen for checking before going back to the office.

All data obtained from the field (point clouds, elevation points and control points) was downloaded into computer using the capabilities of Image Master software (Hamzah, Said 2011; Topcon 2013). The Scanning Application menu in Topcon Imaging Station was used for capture the elevations of the elevation points of the scanned area for post processing application.

\subsection{Levelling using rapid static GPS}

Out of the GPS relative positioning techniques currently being used in surveying, rapid static technique (Berber et al. 2012) was used in this research.

In this procedure, five Sokkia receivers were employed. The process began with one receiver (called the base receiver) being located on an existing control station, while the remaining receivers (called roving receivers) occupied elevation points with unknown coordinates. For the first observing session, simultaneous observations were made from all points to four or more satellites for a time period of 20 minutes since the baseline length was less than $1 \mathrm{~km}$ (Berber et al. 2012).

Except for one, all the receivers were moved upon completion of the first session. This remaining receiver was kept running to serve as the base station for the next observation session. It can be selected from any of the receivers used in the first observation session. Upon completion of the second session, the process was repeated until all elevation points were occupied to complete the survey.

The next step consisted of exporting the collected data of the elevation points to an ASCII file for post processing application.

\section{Results and discussion}

The levelling methods have their advantages and disadvantages with regard to accuracy, cost efficien$c y$, and terrain independence. More precisely, these advantages and disadvantages are project specific.

\subsection{Accuracy and precision}

The elevations of precise levelling were assumed as true values in computation of the accuracies of measurements that were made by each method of levelling. The root mean square errors (RMSE) of elevations were computed as follows: 
$R M S E=\sqrt{\sum_{i=1}^{n}(\text { Elevation from precise levelling - Elevation from the used instrument })_{i}^{2} / n}$

where $n$ is the number of points.

The statistics of elevation differences are given in Table 5. The third and forth columns include the average differences for all points and their maximum values respectively. The fifth column gives the RMSE for each method of elevation determination.

The obtained accuracy is the performance indicator key for the overall surveying operations. The accuracy is highly dependent on the surveying application, technique and the expected resulted production. As it is clear from Table 5 that geometric levelling gives the most accurate height results better than trigonometric or GPS levelling.

The Leica NA 3003 digital level gave the best RMSE value (i.e. RMSE $= \pm 1.2 \mathrm{~mm}$ ), followed by the Leica NA 720 optical level $($ RMSE $= \pm 3.7 \mathrm{~mm})$ and then, expectedly, the Topcon RL-VH4G2 laser level $($ RMSE $= \pm 5.6 \mathrm{~mm})$. This suggests that digital levels can therefore be used at all times for carrying out precision geodetic surveys, for example, establishing primary control networks, crystal deformation studies, monitoring movement of structures etc., and in this respect might completely replace traditional optical and laser instruments in the near future.

Using the total station gave an average operational obtained accuracy better than using scanning total station; where RMSEs are \pm 14.7 and $\pm 16.4 \mathrm{~mm}$. respectively. The worst average operational obtained accuracy was achieved using GPS levelling; where the RMSE is $\pm 19.1 \mathrm{~mm}$.

The values of the obtained RMSE in Table 5 were compared with the permissible limits according to the specifications of ASPRS (American Society for Photogrammetry and Remote Sensing) (ASPRS 1993) as tabulated in Table 6. Considering only the specifications for the highest accuracy (Class I Maps), the obtained results of any levelling method are suitable for generating contours map to any contour interval.

\subsection{Cost efficiency}

This study compares the cost of completing an elevation survey by geometric, trigonometric and GPS Levelling methods that generally use incomparable cost indexes. GPS surveys estimate costs by the number of points surveyed. Whereas, geometric and trigonometric levelling surveys estimate costs by the kilometre distance or area levelled. This dilemma was overcome in this study by comparing the time used completing each elevation survey, since the elevation surveys covered the same exact area.

The total time comparisons between geometric levelling, trigonometric levelling and GPS levelling are presented in Table 7. This table reports that the GPS

Table 5. Comparison of the accuracy of levelling methods

\begin{tabular}{|c|c|c|c|c|}
\hline $\begin{array}{l}\text { Levelling } \\
\text { type }\end{array}$ & Instrument & $\begin{array}{c}\text { Average } \\
\text { error } \\
(\mathrm{mm})\end{array}$ & $\begin{array}{l}\text { Maximum } \\
\text { absolute } \\
\text { error }(\mathrm{mm})\end{array}$ & $\begin{array}{l}\text { RMSE } \\
(\mathrm{mm})\end{array}$ \\
\hline \multirow{3}{*}{$\begin{array}{l}\text { Geometric } \\
\text { levelling }\end{array}$} & $\begin{array}{l}\text { Leica NA } \\
720 \text { (optical) }\end{array}$ & 03.9 & 07.3 & \pm 03.7 \\
\hline & $\begin{array}{l}\text { Topcon } \\
\text { RL-VH4G2 } \\
\text { (laser) }\end{array}$ & 05.1 & 11.3 & \pm 05.6 \\
\hline & $\begin{array}{l}\text { Leica } \\
\text { NA } 3003 \\
\text { (digital) }\end{array}$ & 01.1 & 02.5 & \pm 01.2 \\
\hline \multirow{2}{*}{$\begin{array}{l}\text { Trigono- } \\
\text { metric } \\
\text { levelling }\end{array}$} & $\begin{array}{l}\text { Topcon } \\
\text { GTS710 } \\
\text { total station }\end{array}$ & 12.9 & 27.3 & \pm 14.7 \\
\hline & $\begin{array}{l}\text { Topcon } \\
\text { image } \\
\text { station }\end{array}$ & 15.9 & 33.2 & \pm 16.4 \\
\hline $\begin{array}{l}\text { GPS } \\
\text { levelling }\end{array}$ & $\begin{array}{l}\text { Sokkia } \\
\text { GSR2600 } \\
\text { GPS receiver } \\
\text { and set }\end{array}$ & 19.3 & 40.7 & \pm 19.1 \\
\hline
\end{tabular}

Table 6. ASPRS topographic elevation accuracy requirement for well-defined points

\begin{tabular}{|c|c|c|c|}
\hline \multirow{2}{*}{$\begin{array}{c}\text { Contour } \\
\text { interval in } \\
\text { meters }\end{array}$} & \multicolumn{3}{|c|}{$\begin{array}{c}\text { ASPRS limiting root mean square error } \\
\text { in meters spot or digital terrain model } \\
\text { elevation points }\end{array}$} \\
\cline { 2 - 4 } & Class I $^{*}$ & Class II & Class III \\
\hline 0.5 & 0.08 & 0.16 & 0.25 \\
1.0 & 0.17 & 0.33 & 0.5 \\
2.0 & 0.33 & 0.67 & 1.0 \\
4.0 & 0.67 & 1.33 & 2.0 \\
5.0 & 0.83 & 1.67 & 2.5 \\
\hline
\end{tabular}

* The maps are divided into three classes:

Class I - holds the highest accuracies. Site plans for construction fit this category.

Class II - has half the overall accuracy of Class I. Typical projects may include excavation, road grading, or disposal operations.

Class III - has one third the accuracy or three times the allowable error of Class I maps. Large area cadastral, city planning, or land classification maps are typically in this category. 
Table 7. Time comparison between the different levelling methods

\begin{tabular}{|c|c|c|c|c|c|c|c|}
\hline \multirow{2}{*}{\multicolumn{2}{|c|}{ Levelling method }} & \multicolumn{3}{|c|}{ Geometric levelling } & \multicolumn{2}{|c|}{ Trigonometric levelling } & \multirow{2}{*}{$\begin{array}{c}\text { GPS/levelling } \\
\text { Sokkia } \\
\text { GSR2600 } \\
\text { receiver and set }\end{array}$} \\
\hline & & $\begin{array}{l}\text { Leica NA } 720 \\
\quad \text { (optical) }\end{array}$ & $\begin{array}{l}\text { Topcon RL- } \\
\text { VH4G2 (laser) }\end{array}$ & $\begin{array}{c}\text { Leica NA } 3003 \\
\quad \text { (digital) }\end{array}$ & $\begin{array}{l}\text { Topcon } \\
\text { GTS710 total } \\
\text { station }\end{array}$ & $\begin{array}{l}\text { Image } \\
\text { station }\end{array}$ & \\
\hline \multirow{4}{*}{ 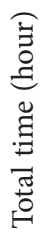 } & $\begin{array}{l}\text { Field } \\
\text { observations }\end{array}$ & 53 & 45 & 32 & 24 & 10 & 10 \\
\hline & Computations & 8 & 7 & 4 & 1 & 8 & 3 \\
\hline & Total & 61 & 52 & 36 & 25 & 18 & 13 \\
\hline & Average & \multicolumn{3}{|c|}{50} & \multicolumn{2}{|c|}{22} & 13 \\
\hline
\end{tabular}

Table 8. Terrain independence for each levelling method

\begin{tabular}{|c|c|c|c|c|c|c|}
\hline \multirow{2}{*}{ Levelling method } & \multicolumn{3}{|c|}{ Geometric levelling } & \multicolumn{2}{c|}{ Trigonometric levelling } & GPS/levelling \\
\cline { 2 - 7 } & $\begin{array}{c}\text { Leica NA 720 } \\
\text { (optical) }\end{array}$ & $\begin{array}{c}\text { Topcon } \\
\text { RL-VH4G2 } \\
\text { (laser) }\end{array}$ & $\begin{array}{c}\text { Leica NA 3003 } \\
\text { (digital) }\end{array}$ & $\begin{array}{c}\text { Topcon } \\
\text { GTS710 } \\
\text { total station }\end{array}$ & $\begin{array}{c}\text { Image } \\
\text { station }\end{array}$ & $\begin{array}{c}\text { Sokkia GSR2600 } \\
\text { receiver and set }\end{array}$ \\
\hline Terrain independence & No & No & No & Yes & Yes & Yes \\
\hline
\end{tabular}

survey took $26 \%$ less time than the comparable geometric levelling survey, or it took $59 \%$ less time than the comparable trigonometric levelling survey. It can be rephrased to state that the total time cost to conduct an elevation project by GPS was $74 \%$ and $41 \%$ less than by conventional geometric and trigonometric levelling respectively.

\subsection{Terrain independence}

Trigonometric and GPS levelling have the additional advantage over geometric levelling by being independent of the terrain surveyed as shown in Table 8. This terrain independence means that there is no difference in trigonometric and GPS levelling whether the terrain is flat or mountainous. Whereas, levelling costs increase significantly in hilly or mountainous terrain relative to flat terrain.

\section{Conclusions}

Not only horizontal positioning has to be determined but also heights of points have to be determined in geodetic studies. The situation of the present instrument or equipment, cost, production velocity, topographical structure of study area must be considered before stating survey procedures.

The methodology and use of the geometric levelling is rather straightforward and well understood. Coverage is highest in flat terrain but is adversely affected in sloping terrain. The best accuracies for levelling can be obtained using the digital levels. The time to set-up and take measurement with a digital level is short comparing with the other types of levels; consequently, the daily coverage primarily depends on transport efficiency. The possibility of making a mistake is much reduced by the electronic reading and data recording. So, taking into account the many capabilities of this type of levels and its readiness for automation and direct integration with other equipment for on-line data processing, it is likely that digital levels, will soon replace conventional levels in most precision geodetic or engineering surveys.

A major advantage of the total station and laser scanner is their capability to cover large area per observation. They can also measure along slopes. Much like with conventional levelling, line-of-sight between the station and the retro-reflector is required. In urban areas and many other terrain types, such as woodland, and along winding roads this may limit the coverage. The possibility of making a mistake is much reduced by the electronic reading and data recording. In comparison with total station, the levelling using laser scanner is rapid and automatic and allows more various possibilities of data representation. Nevertheless, the analysis of point clouds is complex and time consuming and require very expert human operators.

GPS and trigonometric levelling have the additional advantage over geometric levelling by being independent of the terrain surveyed. This terrain independence means that there is no difference in trigonometric and GPS levelling whether the terrain is flat or mountainous. Whereas, levelling costs increase 
significantly in hilly or mountainous terrain relative to flat terrain. In addition, it is true that GPS elevations are less accurate than the elevations gained from the other levelling methods. Generally, GPS/levelling method must be chosen in rural area in which density of point is so low and in which shadow area is not formed.

In contrast, GPS is more cost efficient in large distance projects, because GPS costs remain constant with distance. Whereas, levelling costs increase with distance. Therefore once a project size increases beyond the small project size $(\sim 1 \mathrm{~km})$, GPS is more cost efficient than traditional levelling.

The following levelling methods are recommended for the pre-specified surveying applications:

- Extension of benchmarks in hilly and wide areas in which shadow area is not formed, the GPS/levelling method must be chosen.

- For contouring applications, all levelling methods are suitable for generating contours map to any contour interval.

- It is appropriate to choose the geometric levelling with digital level or the trigonometric levelling with total station or scanning total station for levelling in urban area or semi-urban area in which density of point is so high.

- For the deformation surveys in big structures as bridge, dam, GPS receivers may be used for observations on condition that they are not far from the reference points. In addition, the precise levelling method should be chosen, by using optical level with micrometer attachment and invar staff with $10 \mathrm{~mm}$ graduations or using digital level with bar coded rods, in type of these deformation surveys.

- In construction projects as highway, railway, smoothing area, the trigonometric levelling with total station, the geometric levelling with digital level or laser level, and the GPS/levelling, may be chosen respectively.

\section{References}

American Society for Photogrammetry and Remote Sensing. (ASPRS). 1993. ASPRS accuracy standards for large-scale maps. ASPRS, Bethesda, Maryland, USA.

Berber, M.; Ustun, A.; Yetkin, M. 2012. Comparison of accuracy of GPS techniques, Measurement Journal 45(7): 1742-1746. http://dx.doi.org/10.1016/j.measurement.2012.04.010

Caltrans. 2006. Surveys Manual. California Department of Transportation, State of California, USA.

Ceylan, A.; Inal, C.; Sanlioglu, I. 2005. Modern height determination techniques and comparison of accuracies, in
Pharaohs to Geoinformatics FIG Working Week 2005 and GSDI-8, 16-21 April 2005, Cairo, Egypt.

El Hassan, I. M. 2011. Testing height accuracy of digital and optical levels, in $13^{\text {th }}$ International Surveyor's Congress, 22-24 June 2011, Kuala Lumpur, Malaysia.

Fahd A. A.; Abdullah, E. A.; Abdullah S. A. 2007. Optical, laser and digital levelling: a comparison of accuracy in height measurement, Sudan Engineering Society Journal 53(48): $1-13$.

Ghilani, C. D.; Wolf, P. R. 2012. Elementary surveying. $13^{\text {th }}$ ed. USA, New Jersey, Upper Saddle River: Pearson Education, Inc.

Hamzah, H. B.; Said, S. M. 2011. Measuring volume of stockpile using imaging station, Geoinformation Science Journal 11(1): 15-32.

Ke-liang, D.; Zhou-shi-hong, T. L.; Bing-hai, W. 2010. Level surveying method and accuracy analysis on passenger dedicated line CP-network, in FIG Congress 2010, Facing the Challenges - Building the Capacity, 11-16 April 2010, Sydney, Australia.

Leica. 2013. [online\}, [cited 19 December 2013]. Available from Internet: http://ptd.leica-geosystems.com/en/index.htm

Marin, L. E.; Balcazar, M.; Ortiz, M.; Steinich, B.; HernándezEspriu, J. A. 2008. Comparison of elevation heights using a Differential Global Positioning System (DGPS) and a Total Station, Geofísica International 47(1): 81-83.

Moffitt, F. H.; Bouchard, H. 1992. Surveying. $9^{\text {th }}$ ed. USA, New York: Harper and Row.

Sokkia. 2013. [online\}, [cited 10 December 2013]. Available from Internet: http://sokkia.com/

Topcon. 2013. [online\}, [cited 16 December 2013]. Available from Internet: http://www.topcon.co.jp/en/index.html

Khalid L. A. EL-ASHMAWY (Dr) is associate professor of Surveying \& Digital Mapping at the Department of Civil Engineering, Al-Matria Faculty of Engineering, Helwan University, Egypt. Presently, at Department of Civil Engineering, College of Engineering and Islamic Architecture, Umm Al-Qura University, Makkah, Saudi Arabia.

His area of expertise includes Photogrammetry, Land Surveying, Space photography, Digital Mapping, GIS and development of surveying softwares.

Dr Khalid El-Ashmawy developed many surveying softwares which were published in national and international journals and conferences such as SoftPhotoMap, PHOTOMAP, MATHP, ScanCal, LandSurMap, Calendar, RSA (Road Safety Assessment), and MathDTM softwares. 